\title{
La mirada femenina a cine etnográfico documental.Reassemblage (Trinh T. Minh-ha, 1982)
}

\author{
María Marcos Ramos' (id 0000-0003-3764-7177 \\ Universidad de Salamanca, Facultad de Ciencias Sociales, Departamento de \\ Sociología y Comunicación, Salamanca, España. 37007
}

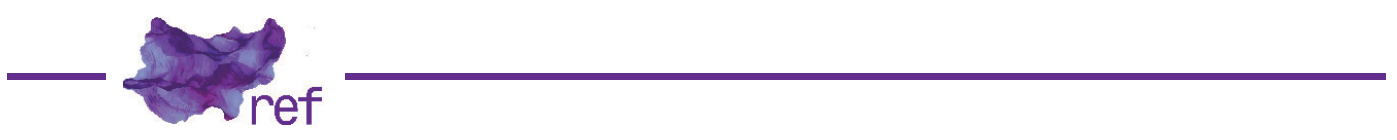

\begin{abstract}
Resumen: El cine documental de la directora vietnamita Trinh T. Minh-Ha ha sido uno de los más interesantes realizados en las últimas décadas por su acercamiento al mundo de la mujer de diversos países y por la reconfiguración del cine etnográfico y del lenguaje filmico. En el presente artículo se abordan las principales características de Reassemblage, su primer trabajo, ahondando en la utilización del lenguaje filmico por parte de la autora y categorizándola dentro de la modalidad reflexiva (Bill NICHOLS, 1997). Además, se analizará el papel de la mujer en el documental etnográfico, al ser realizado por una mujer y ser, además, una mujer el objeto de estudio. Palabras clave: documental; Trinh T. Minh-Ha; Reassemblage; cine etnográfico; lenguaje filmico; mujer.
\end{abstract}

The Feminine Look at The Documentary Ethnographic Cinema. Reassemblage (Trinh T. Minh-Ha, 1982)

Abstract: The documentary of the Vietnamese director Trinh T. Minh-Ha has been one of the most interesting made in recent decades due to its approach to the world of women in different countries and to the reconfiguration of ethnographic cinema and film language. This article addresses the main characteristics of Reassemblage, her first work, delving into the use of film language by the author and categorizing it within the reflective mode (Bill NICHOLS, 1997). This work will analyze the women's role in the ethnographic documentary, as it is carried out by a woman, and has a woman as the object of study

Key words: documentary; Trinh T. Minh-Ha; Reassemblage; ethnographic cinema; film language; women.

O olhar feminino para o cinema etnográfico documentário. Reassemblage (Trinh T. Minh-ha, 1982)

Resumo: $O$ filme documentário da diretora vietnamita Trinh T. Minh-Tem sido um dos mais interessantes realizados nas últimas décadas pela sua aproximação ao mundo da mulher de diversos países e pela reconfiguração do cinema etnográfico e da linguagem filmica. No presente artigo abordam-se as principais características de Reassemblage, seu primeiro trabalho, aprofundando a utilização da linguagem filmica por parte da autora e categorizando-a dentro da modalidade reflexiva (Bill NICHOLS, 1997. Além disso, este trabalho analisará o papel da mulher no documentário etnográfico, pois é realizado por uma mulher, tendo como objeto de estudo uma mulher.

Palavras-chave: documental; Trinh T. Minh-Ha; Reassemblage; cine etnográfico; lenguaje fílmico; mujer.

\section{Introducción}

Estudiar la figura de Trinh T. Minh-ha supone analizar su trayectoria no solo como documentalista sino también como profesora, música, escritora y teórica de la imagen. Ninguna de 
sus facetas puede ser estudiada de forma aislada, ya que cada una de ellas está implícita en todas las demás. No se pueden entender, por ejemplo, sus películas documentales sin ese interés suyo que le lleva a preguntarse por temas formales de la imagen, como el encuadre, el montaje o el uso de los códigos sonoros, entre otros. Tampoco puede aislarse su faceta como música en sus proyectos documentales, ya que concede la misma importancia a la imagen y a la música en sus trabajos. Sin embargo, en sus documentales no queda tan claro cuál de los dos conceptos -imagen y sonido- está relegado, o cuál de los dos se superpone a cuál, ya que ambos tienen la misma importancia, pues "imagen y sonido construyen discursos paralelos pero prácticamente desarticulados, son complementarios sin dejar de ser independientes" (Antonio ZIRIÓN, 2018).

Nacida en Hanoi (Vietnam) en 1952, se traslada a Estados Unidos en 1970, donde cursa estudios de composición musical, etnomusicología y literatura francesa en la Universidad de Illinois, en la que se doctora. Su trabajo académico como profesora de estudios de género en la Universidad de California está presente en la mayoría de sus trabajos audiovisuales, donde la mujer es un eje fundamental. Sin embargo, a pesar de que la mujer es un tema central en sus documentales, Trinh T. Minh-ha ha indicado que

a veces me molesta que me llamen cineasta feminista, según quién me lo llame y en qué contexto lo haga. (...) Por otra parte, las etiquetas circulan siempre en nuestro mundo y a veces son simplemente un modo de conocernos. Ser feminista significaría entonces sostener esas acciones, esa conciencia crítica respecto a la sociedad y sus opresiones. (Susana BLAS, 2006, p. 28-29)

Hay investigadores que fechan la participación de la mujer de forma generalizada como directoras a partir de los años 90 renovando el discurso feminista. Este cambio de paradigma sobre quién mira supuso el desarrollo de los estudios de género y la consideración de las mujeres que se dedicaban al cine como "sujetos sociales renovadores y trasgresores de un estatus y de una identidad de género" (Patricia TORRES SAN MARTíN, 2014, p. 108).

Trinh T. Minh-ha no trata de realizar con sus documentales un tratado sobre la escritura o la filmación femenina, sino que se acerca más a la denominada etnografía feminista que "atiende a la subjetividad de las mujeres a través de la singularidad de sus historias de vida con el propósito de pensar la complejidad de las relaciones de poder que afrontan las mujeres en los contextos sociales en los que se debaten" (Cristina VEGA SOLís, 2000). Las mujeres, además de otros colectivos, serán objeto de estudio para ella, especialmente el encuentro entre mujeres y su modo de vida, pero no las aísla para analizarlas, sino que las examina dentro de la sociedad de la que forman parte, dándoles mayor o menor protagonismo en función del trabajo suyo que se analice.

La conciencia crítica con respecto a la sociedad es el pilar central de todos sus trabajos. Ese cuestionamiento ideológico sobre lo político influye en su modo de hacer cine pues para ella "el filme tiene que ser político en todos sus aspectos, incluso en los formales y estructurales, no solo en su contenido" (BLAS, 2006, p. 28). Precisamente es este planteamiento el que está más presente en sus películas, especialmente en aquellas en las que la frontera que separa el cine de ficción, argumentativo, del documental está más difusa. E incluso también cuestiona, dentro de este paradigma, qué es ficción y qué es realidad. ¿Es más real una historia ficcionada o solo retratada? ¿Se puede jugar con la ficción y la realidad sin hacer cómplice de este juego al espectador? ¿Hasta qué punto es lícito en el documental representar la realidad en el sentido de recrear? ¿Es la realidad filmada otra realidad o es una mera representación de esta? Estas y otras cuestiones, como el nuevo cine etnográfico, serán planteadas en este trabajo a través del análisis de uno de sus trabajos audiovisuales, Reassemblage (1982) su primera película y obra que marcaría su forma de hacer cine, además de cuestionar una de las ramas del cine documental más importantes, como es el cine etnográfico.

\section{El nuevo cine etnográfico}

Cuando surge el cine documental', en 1922, con la película Nanuk, el esquimal de Robert Flaherty, no solo se inicia una nueva forma de hacer cine, sino que el documental se vincula con el denominado cine etnográfico, una tipología más ligada a la antropología que al cine (Ma Elisa SÁNCHEZ SANZ, 1995, p. 270) en la que se trataba de "documentar" mediante la "presentación de hechos reales de forma que los haga creíbles y elocuentes para la gente" (William STOTT, 1976, p. 73) cómo viven personas de lugares lejanos. La representación del "salvaje" o

\footnotetext{
1 "Con el enfoque documental, el cine regresa a sus principios básicos... Mediante la selección, eliminación y coordinación de elementos naturales, evoluciona una forma fílmica que es original y no se limita a la tradición teatral o literaria... El cine documental es una forma artística oiginal. Ha asumido los hechos, dentro de un nivel original propio. Cubre la parte racional de nuestras vidas, desde el experimento científico hasta el estudio del paisaje poético, pero nunca se aleja de los hechos" (Hans RICHTER, 1998, p. 183).
} 
del "primitivo" de estos primeros años se realiza de dos formas, desde el deber realista que tiene el investigador pero él es mostrado desde un punto de vista fantástico en el que viven salvajes exóticos ya que según Cristina Vega Solís, siguiendo las ideas del antropólogo visual Jay Ruby (1995), el cine etnográfico mostraba individuos exóticos, que viven en tierras lejanas, realizando "actividades de subsistencia, relaciones sociales, religión, mitos, ceremonias rituales, etc" (VEGA SOLÍS, 2000).

En estas películas está más presente, debido al origen de su propia concepción, el qué se cuenta sobre el cómo se cuenta, ya que el director debe cuestionarse cómo reunir el material necesario para crear una investigación que pueda ser vista en forma de película por sus estudiantes (John COLLIER, 1986, p. 130). Estas películas se convierten, por tanto, en "una herramienta inigualable para explorar, captar y coleccionar las peculiaridades del mundo" (Roger CANALS, 201 1, p. 67). Al director también se le presuponía una cierta objetividad en la recogida de los datos, esto es, de testimonios y hechos reales filmados. Por tanto "ha de ser un mero testigo de lo que filma, no debe interpretar la realidad, ni interferirla, ni alterarla ni manipularla. Debe ser discreto y respetuoso con ella, aséptico, prescindiendo de ideas tendenciosas" (SÁNCHEZ SANZ, 1995, p. 271). El cine etnográfico tradicional "se caracteriza por un repudio a cualquier tentativa artística, se esmera en crear un discurso de sobriedad, sin confesar que, para construir dicho discurso, son también necesarias estrategias estéticas" (Natalia MOLLER, 2011). Sin embargo, ya desde el momento en el que el director decide filmar un tema y no otro, con un encuadre, con una angulación, con una determinada iluminación, etc. e incluso en el montaje, al seleccionar una imagen y no otra, una voz y no otra, una transición y no otra, etc. interpreta la realidad, interfiere en ella y la adjetiva. Y estas son, quizás, las principales diferencias entre quienes han utilizado el cine etnográfico como medio de estudio y los que lo han hecho como arte, los que han experimentado con el lenguaje audiovisual, con la fidelidad de la representación e incluso con la frontera que separa la ficción del documental.

A medida que el cine documental fue evolucionando, se convirtió para los creadores "en un espacio heterodoxo de experimentación y expresión" (María Luisa ORTEGA, 2007, p. 19). Esto también influyó en el cine etnográfico, evidentemente, que no permanece inalterable ante los cambios. Su concepción originaria también va mutando y se ve influenciada por otras corrientes, como la antropología visual. A veces los límites entre uno y otro son difusos, aunque a medida que ambos se asientan, se va ajustando la forma en la que cineastas y antropólogos se acercan al concepto de objetividad para asumir otros métodos de legitimación que introducen nuevos modelos para el cine etnográfico y para la antropología visual (David MACDOUGALL, 1995 , p. 129). El mundo académico, que no permanece ajeno a esta disyuntiva, se ha preocupado por definir qué es una película etnográfica indicando que es "un conjunto de signos cuya función es el estudio del comportamiento de una comunidad" (Sol WORTH, 1995, p. 206). Aunque esta parece una definición restrictiva, también se ha indicado que no es tanto la película la que debe ser etnográfica o no, ya que cualquier película empleada de forma etnográfica, es decir, con la finalidad de estudiar una comunidad, puede ser englobada en esta categoría (MACDOUGALL, 1995; WORTH, 1995).

En los sesenta años que separan Nanuk, el esquimal de Robert Flaherty y Reassemblage de Trinh T. Minh-ha, el mundo y el modo que un director tiene para aproximarse a él se ha transformado mucho. No solo ha cambiado la técnica, que ha evolucionado significativamente, sino también la forma en que se utiliza ${ }^{2}$. Sirva de ejemplo la filmografía de Jean Rouch que, sin duda alguna, reconfigura el cine etnográfico desde los años 50 hasta los años 80 . Rouch, uno de los máximos exponentes del cinéma verité, hace presente en su forma de hacer cine a dos de los grandes documentalistas, como son Dziga Vertov y Robert Flaherty. Del primero adopta la libertad de movimientos de la cámara y del segundo su metodología participativa para conseguir la verdad de la ficción que, como señala CANALS (201 1, p. 76) "para Rouch la objetividad no se debe entender como una adecuación del filme a una supuesta verdad inherente al mundo, sino, sobre todo como una consecuencia de la reflexividad, es decir, de hecho de hacer manifiestos los mecanismos utilizados durante el rodaje así como el carácter esencialmente interpretativo de toda la película etnográfica".

Los intereses de los documentalistas son otros, pues mostrar algo, documentar algo, ya no es solo el único objetivo de los directores sino que también importa cómo se muestra, cómo se codifica ese mensaje. El cine etnográfico ha cambiado mucho desde sus orígenes, a pesar de que conserva esa esencia que le hace único y particular: mostrar al mundo cómo viven sociedades diferentes a la nuestra.

\footnotetext{
${ }^{2}$ En este nuevo contexto se hace necesario un nuevo lenguaje en el discurso audiovisual o más bien, un proceso de deconstrucción "de las convenciones discursivas, mediáticas y científicas, que prevalecieron en la etnografía clásica, se convierte entonces en una tarea básica para las siguientes generaciones de etnógrafos visuales" (MOLLER, 2011).
} 
El cine etnográfico de Trinh T. Minh-ha se caracteriza por "desobedecer y burlar límites y categorías (...) establece en sus textos y películas una forma de hablar que reflexiona sobre sí misma y que puede acercarse mucho a un sujeto, sin apoderarse de él" (MOLLER, 2011).

Trinh T. Minh-ha mira, observa, analiza, reflexiona en su cine etnográfico no solo sobre el sujeto (o la realidad) sino también sobre el lenguaje que se puede utilizar para hacer esta reflexión. Su trabajo es "una reinvención de la etnografía, un giro hacia lo poético, pero también como práctica crítica y deconstructiva del cine etnográfico tradicional" (MOLLER, 2011) cuestionando si el arte es transparente o no (Robert STAM, 2001, p. 182). El teórico Ismail Xavier analiza las discusiones en torno a la idea de "transparencia narrativa" y a las propuestas de deconstrucción del discurso cinematográfico de la tradición, en cuyo centro se hallan los debates acerca de la explicitación del sujeto de la enunciación y de la reflexión del lenguaje fílmico (XAVIER, 2008), aspectos muy presentes en el cine de Trinh T. Minh-Ha.

\section{La mirada de Trinh T. Minh-Ha}

Tal y como la propia directora afirma en su película Reassemblage (1982), su intención no es hablar sobre, sino hablar cerca. Su cine se centra en hablar "cerca" de temas tan variados como

el feminismo, la mirada hegemónica sobre la diferencia y la desigualdad sociocultural, el problema de la verdad en las ciencias antropológicas y el cine documental, la cuestión de la identidad, las hibridaciones y los desencuentros interculturales, así como la libre experimentación artística en torno al medio cinematográfico. (ZIRIÓN, 2018)

Su mirada sobre estos temas, tal y como ella misma afirma, "son maneras de pensar sobre mis propios posicionamientos y sobre las herramientas creativas y estéticas" (Ana AMADO; Mónica SZURMUK ${ }^{3}, 2017$, p. 135), eliminando la objetividad que se le presuponía al director de cine etnográfico, pues deja de ser testigo para ser un sujeto activo en la historia, interpretando, además, la realidad, ya que "que "la simple presencia de una cámara modifica el comportamiento de quienes saben que esta se halla ahí presente" (Laurent JULLIER, 2006, p. 101).

Por tanto, la mirada de Trinh T. Minh-ha es una contemplación implicada que opina sobre el hecho retratado y busca una reacción en el espectador. Su cine se correspondería a la modalidad reflexiva descrita por Nichols (1997), en la que el director no retrata el mundo histórico, sino que se cuestiona cómo se habla acerca de este mundo histórico. En este sentido, "ser reflexivo, en antropología, significa que los antropólogos han de revelar de manera sistemática y rigurosa su metodología y a sí mismos en tanto instrumentos en la generación de información" (RUBY, 1995, p. 153).

Para ello, Minh-ha no solo ejercerá las labores propias del director de documentales, sino que participará con sus comentarios en el propio relato a modo de metacomentarios. La reflexividad en este tipo de documentales "se reduce en muchos casos a una cuestión de naturalizar el yo y el tú, las posiciones" (VEGA SOLís, 2000). En los relatos documentales adscritos a esta modalidad no solo se tiene en cuenta la forma y el estilo, sino también la estructura, las convenciones, los efectos, las expectativas. El realizador no suele señalar cuestiones éticas de forma directa o explícita, sino que expone mediante la yuxtaposición de planos su posición frente al mundo para que sea el espectador el que se posicione con respecto a lo mostrado (NICHOLS, 1997).

Es el cine documental reflexivo, como el que crea Trinh Minh-ha, el que en mayor medida más cuestiona los límites entre documental y ficcional, entre cine argumentativo y no argumentativo, entre realidad y ficción, pues parece confirmar que "todo film narrativo documenta una ficción, pero todo film documental ficcionaliza una realidad preexistente" (Santos ZUNZUNEGUI, 1984 , p. 60). Los documentales reflexivos siguen la premisa de Zunzunegui al no cuestionarse si son menos realistas por ficcionalizar una realidad que ya existía pues utilizan todas las técnicas del lenguaje audiovisual que consideran necesarias, de manera consciente, con el fin de retratar la realidad, sin restarle por ello un ápice de verdad, asumiendo el documentalista un compromiso de veracidad con el espectador (Carl PLANTINGA, 2005).

Trinh Minh-Ha, siguiendo la afirmación de Ruby (1995, p. 165) en la que indica que "ser reflexivo es virtualmente sinónimo de ser científico", explica los motivos por los que un documentalista debe utilizar las técnicas "reflexivas", ya que "incluirían la inserción de una narrativa verbal o visual sobre el antropólogo, la metodología adoptada y la condición de producción” (Trinh MINH-HA, 2007, p. 241).

\footnotetext{
${ }_{3}$ Todas las citas extraídas de la referencia Ana Amado y Mónica Szurmuk pertenecen a una entrevista que las autoras realizaron a Trinh T. Minh-ha con motivo de su asistencia a Buenos Aires al Festival Internacional de Cine y Formación en Derechos Humanos de las personas migrantes que tuvo lugar del 16 al 23 de septiembre de 2015.
} 
Cristina Vega Solís (2000) señala que Trinh Minh-Ha no mira desde un lugar sino más bien es un modo de mirar. La propia directora en declaraciones recogidas por Vega Solís analiza su mirada:

en el momento en que la de dentro da un paso fuera del interior, deja de ser simplemente una de dentro (y vice versa). No exactamente la lgual, no exactamente la Otra, ella se mantiene en ese umbral indeterminado en el que constantemente se inclina hacia dentro y hacia fuera (...) Ella es esa Otra/lgual Impropia que siempre va de aquí para allá con al menos cuatro gestos: el de afirmar "Yo soy como tú" mientras persiste en su diferencia; y el de recordar "Yo soy diferente" mientras sacude toda definición de la alteridad a la que llega. (VEGA SOLÍS, 2000)

Trinh T. Minh-Ha reformula las concepciones sobre el sujeto y el lenguaje dominantes en el cine más clásico y, entre otras cuestiones, se replantea, al igual que lo hicieran otros directores de la nueva ola de post-documentales. No solo es cuestionada la figura del autor, sino también la funcionalidad del propio lenguaje referencial (Pablo PIEDRAS, 2012, p. 39), liberándola "de su falsa identificación con el mundo fenoménico y de su autoridad asumida como medio de reconocimiento sobre el mundo" (MINH-HA, 2007, p. 225).

\section{Filmografía}

Desde que inició a principios de los años ochenta su carrera como documentalista, Trinh T. Minh-Ha ha realizado ocho películas documentales con las que "rompe radicalmente las reglas del lenguaje cinematográfico y trastoca todas las convenciones del cine documental, provocando a su vez un profundo cuestionamiento acerca del sentido de la mirada antropológica y las formas clásicas de representación visual de otras culturas" (ZIRIÓN, 2018). Su filmografía está compuesta por ocho trabajos: Reassemblage (1982), Naked Spaces - Living is Round (1985), Surname Viet Given Name Nam (1989), Shoot for the Contents (1991), A Tale of Love (1995), The Fourth Dimension (2001), Night Passage (2004), y Forgetting Vietnam (2015). Por temas de espacio en este artículo se analizará solo Reassemblage (1982), por ser una de sus películas emblemáticas por la utilización del lenguaje audiovisual con que fue creada, y también por centrar su objeto de estudio -o tema fílmico- en las mujeres. Esta película documental puede servir de ejemplo para entender la filmografía posterior de Trinh T. Minh-Ha.

\subsection{Reassemblage (1982)}

En la primera de sus películas documentales, el mediometraje Reassemblage (1982), Trinh T. Minh-Ha se acerca a Senegal, un país desconocido para ella, con el que poder mirar desde lejos y siempre teniendo presente su posición de no-saber, pues, según indica la propia directora utilizando la voz en off en los primeros minutos de la película: "lo que yo quería hacer era una película afirmando mi no-saber y así empezó la pregunta: “¿Una película sobre Senegal?", “¿Pero qué sobre Senegal?”” (AMADO; SZURMUK, 2017, p. 136).

Reassemblage (1982) no es solo una película con la que conocer Senegal y a sus gentes, sino también es, como todas las películas que realiza con posterioridad la directora vietnamita, una reflexión sobre el propio cine, sobre el modo de hacerlo y de interpretarlo, y, lo más importante, un cuestionamiento sobre el cine etnográfico convencional. Realizado bajo una apariencia de cine etnográfico, Minh-Ha dirige un documental que narra la vida cotidiana de la gente de Senegal, especialmente de las mujeres. A pesar de utilizar todos los tropos del cine etnográfico, como lugareños bailando con su vestimenta típica, mujeres portando niños, hombres y mujeres trabajando en el campo, etc., que forman parte de las cuestiones analizadas por la etnografía más arquetípica, Reassemblage (1982) no es un documental etnográfico convencional, tal y como lo demuestra su título, que alude directamente a Derrida y a su deconstrucción, "a lo fragmentario y a lo construido" (Erika BALSON, 2018). Minh-ha realiza un documental "anti-etnográfico, una película que desmantela reflexivamente la objetivación y la exotización de la otredad" (BALSON, 2018). Redefine, por tanto, el cine etnográfico utilizando para ello el lenguaje cinematográfico con el fin de "poner en evidencia que es la representación la que constituye al objeto representado" (MOLLER, 201 1, p. 2). Para ello, Trinh T. Minh-Ha utiliza los primeros planos y primerísimos primeros planos, además de insertar de forma constante "repeticiones" de palabras y motivos claves. Estas repeticiones no son, exactamente, iguales, sino que "se cambia una palabra, una entonación, la sintaxis de la frase, transformando el significado de la imagen en inestable y polisémico" (BLAS, 2006, p. 28). Se cuestiona, por tanto, la veracidad que se le presupone al género documental y, por extensión, al etnográfico.

En Reassemblage (1982) Trinh T. Minh-Ha ya se plantea todos estos temas y los aplica para, por ejemplo, cuestionar el uso que tradicionalmente ha hecho el cine etnográfico de los

4 "Reassemblage is better understood as antiethnography - a film that reflexively dismantles the objectication and exoticization of otherness which mark the ethnographic and colonial projects alike-“. (Traducción de la autora). 
desnudos de las mujeres filmadas, donde se abusa de enseñar cuerpos desnudos, especialmente de mujeres. Tal y como indica Vega Solís,

más que la desnudez, es el espectáculo de cubrir y descubrir el cuerpo, el deseo del espectador occidental de comprobar cómo son desnudas, lo que tematiza el cuerpo de la mujer. Una actividad que si estuviera protagonizada por mujeres blancas sería inmediatamente tachada de pornográfica. (2000)

Trinh hace alusión a esto en un comentario que realiza a modo de voz en Reassemblage: "un hombre asistiendo a una presentación de diapositivas sobre África se dirige a su esposa y le dice con culpa en la voz: He visto pornografía esta noche". El modo en que filma el cuerpo femenino está marcado por el uso de encuadres fragmentados, en el que no aparece nunca el cuerpo femenino entero. La cámara, además, no permanece estática. Ella se mueve por el encuadre para que en ningún momento la imagen esté fija, para que no haya una recreación en la mostración del cuerpo desnudo. La imagen está acompañada por sonido que "establece una serie de paralelismos con situaciones que no están ilustradas en la imagen, pero que remiten a cuestiones del encuentro intercultural, problemas de la etnología, de la descripción de la alteridad y cuestiones de género" (Gustavo SORANZ, 2018, p. 13).

Minh-ha no solo es una documentalista con el único objetivo de mostrar una realidad a los espectadores, tal y como se ha indicado con anterioridad. Ella no solo se limita a esto, sino que busca con sus trabajos algo más al no poder desprenderse de todas sus facetas, como la de teórica y crítica de la imagen, y utiliza sus documentales para cuestionarse la validez de la imagen y para "jugar" con el lenguaje audiovisual buscando en él nuevos límites, nuevos usos de lo convencional, para poder dotar de un nuevo significado al relato audiovisual, ya que "al significado aparentemente completo y concluso del discurso científico, Trinh contrapone signos despojados de significado, o, mejor dicho; de significado oscilante, resbaladizo" (MOLLER, 2011 , p. 2).

Además de trabajar y cuestionar el uso por parte del cine de los códigos visuales, Minh-Ha también se replantea el uso de los códigos sonoros, en parte por su condición de compositora musical y por sus estudios sobre etnomusicología. En sus películas, la banda sonora -música, efectos sonoros, diálogos y sonidos- juega un papel fundamental y no se supedita a la imagen, sino que conforma un relato independiente. En sus películas hay música de estudio, pero también música grabada en directo. Hay, además, otros códigos sonoros, como,

"los ruidos y sonidos captados en sonido directo durante el trabajo de campo, estos son a menudo utilizados como recursos sonoros no sincrónicos para desnaturalizar la asociación con la imagen y adquirir otras funciones, musicales y rítmicas"6 (SORANZ, 2018, p. 21).

Sobre lo que señala SORANZ en su cita referido a la sincronización del sonido y la imagen, algo muy habitual en el cine clásico, Trinh T. Minh-Ha (2007, p. 228) ha indicado que "sincronizar la voz y el movimiento de los labios es la norma legitimada; es un "imperativo", no tanto para reproducir la realidad (lo que ya se ha reconocido de sobra entre los artífices de los hechos reales) como para mostrar a la gente real en lugares reales desarrollando actividades reales".

Hay que destacar del documental Reassemblage (1982) el uso tan creativo que la directora vietnamita hace de la banda sonora, siendo una de las fuerzas estéticas de la película, reafirmando, además, ese interés por deconstruir la práctica fílmica tradicional, ya que con la articulación que se hace de imagen y sonido, "Ia película desnaturaliza la representación de los cuerpos, del espacio y de la acción que registra en el Senegal, llamando la atención sobre la política de representación y no para el el tema"' (SORANZ, 2018, p. 22).

Trinh T. Minh-ha presta especial atención a uno de los códigos sonoros que, a veces, suele ser de los menos trabajados en la narrativa convencional como es el silencio. Si en el cine convencional el silencio apenas tiene protagonismo en la película documental con la que la directora comienza su trayectoria fílmica es un elemento fundamental, llegando incluso a dejar ciertas escenas sin sonido, sin nada de sonido, totalmente silenciosas. De este modo, "el uso del silencio en esas películas hace el trabajo con el sonido visible (...), los silencios asumen un carácter activo y marcando, contribuyendo a la elaboración de una narrativa en la que la imagen y el sonido expresan dimensiones sensibles" ${ }^{8}$ (SORANZ, 2018, p. 23).

\footnotetext{
${ }^{5}$ La cita original, traducida por la autora, es la siguiente: "estabelece uma série de paralelos com situações que não estão ilustradas na imagem, mas que remetem a questões do encontro intercultural, problemas da etnologia, da descrição da alteridade e questões de gênero" (SORANZ, 2018, p. 13).

6 "Aos ruídos e sons captados em som direto durante o trabalho de campo, estes são frequentemente utilizados como recursos sonoros não sincrônicos de modo a desnaturalizar a associação com a imagem e adquirir outras funções, musicais e rítmicas. Há ainda o uso do silêncio como recurso narrativo" (Cita original, traducción de la autora). 7 "o filme desnaturaliza a representação dos corpos, do espaço e da ação que registra no Senegal, chamando a atenção para a política da representação e não para o tema" (Referencia original. Traducción de la autora).

8 "O uso do silêncio nesses filmes torna o trabalho com o som visível (...) os silêncios assumem um caráter ativo e marcante, contribuindo para a elaboração de uma narrativa em que imagem e som expressam dimensões sensíveis" (Referencia original. Traducción de la autora).
} 
Trinh T. Minh-ha utiliza, además, su propia voz como hilo narrativo a modo de meta-comentarios, como el que realiza en el inicio, cuando introduce el tema de estudio, o el que hace cuando se muestran los pechos de la mujer senegalesa, por ejemplo. El hecho de utilizar su propia voz en el documental, algo habitual en los últimos años en las narrativas subjetivistas (PIEDRAS, 2012 , p. 39), hace que este pueda ser encuadrado en la modalidad reflexiva realizada por Nichols ${ }^{9}$ (1997). Sus preguntas y reflexiones en torno al tema tratado logran que se incluya la crítica, pero no solo la de la autora, sino que busca, a través de la formulación de preguntas y respuestas, la reacción del espectador, el cuestionamiento de este sobre la realidad, o la aparente realidad, sobre el tema en el que la directora ha centrado su atención, buscando también esa mirada reflexiva en el espectador midiendo el impacto en la audiencia.

Sobre este aspecto, el cuestionamiento de la veracidad de los documentales que se produce de forma generaliza en el mundo académico y también entre los autores de documentales, Trinh T. Minh-ha (2007, p. 223) indica que "la verdad, aunque "se pille al vuelo", no se manifiesta en nombres ni en imágenes (fílmicas), y no deberíamos dar por sentado que el significa-do queda cerrado con lo que se dice o se muestra".

El cine de Trinh T. Minh-ha interroga sobre realidad y ficción, que es uno de los asuntos claves de su cine, además de para el cine documental en general que, a finales de los años ochenta y principios de los noventa, se preguntará con los denominados post-documentales dónde están los límites de la ficción o la realidad. Alexander Kluge ahonda en los límites de los documentales a la hora de representar la realidad frente al cine ficcional o argumentativo:

Un documental se rueda con tres cámaras: 1) la cámara en el sentido técnico; 2) la mente del cineasta; 3) los patrones genéricos del cine documental, que se basan en la expectación del público que lo auspicia. Por esta razón no se puede decir simplemente que el cine documental retrate hechos (...) En sí mismo y por sí mismo, el documental no es más realista que la película. (KLUGE, 1998, p. 4)

Si tradicionalmente se ligaba documental con realidad, los nuevos documentalistas cuestionarán esta analogía e indicarán que "no funciona para ocultar o excluir lo que se normaliza como "no objetivo", porque comprende la dependencia mutua de realismo y "artificiosidad" en el proceso de filmación. Reconoce la necesidad de componer (sobre) la vida viviéndola o haciéndola" (MINH-HA, 2007, p. 235).

Así, volviendo a la idea originaria con la que Minh-ha realiza su documental -conocer Senegal- quizás se deba cuestionar qué realidad de Senegal nos ha mostrado la directora vietnamita: si es realidad o una restitución de esta. Si el Senegal y, por extensión, sus gentes, mostrados son menos reales si son recreados o si lo que los lugareños nos cuentan es más real por estar recogido en un documental o si tal vez fuera menos real en una película de ficción, o quizá no. Quizás no se deba prestar tanta atención al medio como a lo mostrado, es decir, no debería cuestionarse si lo representado en imagen es más o menos real si se trata de cine documental o de cine ficcional.

Minh-ha revela las estrategias y los métodos utilizados, rompe la distancia entre autor y sujeto observado, algo muy habitual en los documentales contemporáneos, e introduce su propia visión con comentarios que no son imparciales, sino apelaciones abiertas al espectador, para construir un significado en sus películas. Reassemblage (1982) es, en este sentido, un documental en el que se pueden observar todas estas características, marcando las pautas a trabajos posteriores de la directora, quien ha utilizado muchos de los elementos empleados por primera vez en este trabajo, para ahondar sobre ellos y experimentar más en sus próximos trabajos, y también a otros documentalistas coetáneos a la directora.

\section{Conclusiones}

Este primer trabajo de Minh-ha, a pesar de pasar desapercibido al comienzo -la misma autora indica que "mi película Reassemblage (1982) comenzó con un espectador. Yo también pasé por la prueba de tener solamente un espectador (...) no conocía a la persona, lo que recuerdo es que era una mujer" (AMADO; SZURMUK, 2017, p. 133)- sirve como punto de partida y marcará las señas de identidad del cine de la directora. Con este trabajo, además, se cuestionará el cine etnográfico tradicional, además de la pretendida objetividad con el que

\footnotetext{
9 "Si el mundo histórico es un lugar de encuentro para el proceso del intercambio y la representación sociales en la modalidad interactiva, la representación del mundo histórico se convierte, en sí misma, en el tema de meditación cinematográfica de la modalidad reflexiva. En vez de oír al realizador implicarse únicamente de un modo interactivo (participativo, conversacional o interrogativo) con otros actores sociales, ahora vemos u oímos que el realizador también aborda el metacomentario, habiéndonos menos del mundo histórico en sí, como en las modalidades expositiva y poética o en la interactiva y la que se presenta a modo de diario personal, que sobre el proceso de representación en sí. Mientras que la mayor parte de la producción documental se ocupa de hablar acerca del mundo histórico, la modalidad reflexiva aborda la cuestión de cómo hablamos acerca del mundo histórico" (NICHOLS, 1997, p. 93).
} 
supuestamente se caracterizaba este cine y, por ende, el cine documental frente al ficcional. A este respecto, Nichols (1997, p. 111) afirma que en el documental Reassemblage se "desconstruye[n] con éxito muchas de las convenciones de la objetividad en el documental, destacando en tono reflexivo la naturaleza condicional de cualquier imagen y la imposibilidad de llegar a una verdad indiscutible".

También ponía en cuestión el supuestamente afán didáctico que tenía el cine etnográfico al nacer con la intención de mostrar al mundo la vida de personas que viven en países lejanos. En su trabajo, Minh-ha pone de relieve estas características al interrogarse primero ella como directora y después al público como espectador. Pero también se preguntará sobre su propia mirada, tal y como ella misma dice en el documental cuando filma a una mujer senegalesa "mirándola a ella por el lente. La veo convertirse en mí, convertirse en mía. Entrando en la única realidad de signos, en la cual yo misma soy un signo", negándose a personificar la estabilidad representacional del Orden Simbólico. Su mirada, más que feminista femenina, se centra en África y, en especial, en las mujeres africanas, todo ello visto desde su mirada, una mirada femenina con la que observa el mundo.

Su obra nos permite múltiples lecturas, múltiples interpretaciones y, por encima de todo, nos hace replantearnos nuestra posición como espectadores. Su obra no es de visionado fácil, pues requiere no tanto una preparación intelectual, sino una buena predisposición hacia el visionado. La intención de Trinh T. Minh-ha de implicar al espectador e inculcarle una mirada reflexiva es cuestionada por algunos académicos como Henrietta MOORE (1994), quien indica que este tipo de documentales puede reforzar prejuicios y estereotipos en lugar de cuestionarlos al no quedar clara la intención de la directora, especialmente con un espectador medio, poco acostumbrado, ya que "esa pluralidad de voces, esos textos deconstructivistas, terminarían estando descontextualizados; y como ninguna voz es privilegiada, las representaciones podrían interpretarse bajo un empirismo ingenuo, donde palabras e imágenes hablan por sí mismas, interpretándose la imagen/ sonido como una narrativa que sólo corrobora lo que se muestra" (BLAS, 2006, p. 31).

Esta crítica también la ha recibido la autora sobre sus libros, calificados como difíciles y complejos. Sobre este aspecto, Trinh T. Minh-ha declara en una entrevista lo siguiente (Akira MIZUTA, 2012):

He oído a un gran número de académicos decir que mis libros son muy difíciles. Y yo esto no lo niego. Pero, por otra parte, conozco gente que dejó la escuela a los quince años y que no ha tenido ninguna preparación teórica, y que llega a mis libros por accidente, y que aunque no pueden leer muchas páginas de una vez... leen algunas y me dicen que es increíble porque sienten afinidad con el proceso de mi pensamiento, que pueden seguirlo muy bien. Si uno simplemente observa cómo opera el lenguaje - creando todos esos circuitos dentro de él mismo- y cómo trabaja con nosotros constantemente, entonces estos filmes son fáciles de "entender".

Que sean o no sencillos de entender no parece ser la cuestión clave de su cine. Su obra ha conseguido cuestionar los cánones y normas de la academia, convirtiéndola en una autora indispensable no solo en el campo documentalista, sino también en nuevos lenguajes en campos como las artes visuales, pues "su mirada y su voz crítica, su valiente experimentación artística y sofisticado valor estético, su infatigable vocación etnográfica y la profunda interrogación que provoca frente a los discursos dominantes" (ZIRIÓN, 2018) convierten a Trinh T. Minh-ha en una de las mayores y más importantes referentes del nuevo cine documental etnográfico. Al margen de las técnicas, sí que es reseñable que ella, como mujer, sitúe en el centro de sus trabajos la situación de la mujer en países como Senegal, Vietnam, China o Japón, utilizando, además, un lenguaje audiovisual alejado de la normatividad y construyendo un nuevo relato, una nueva forma de ver y estar en el mundo.

\section{Referencias}

AMADO, Ana; SZURMUK, Mónica. "Narrar la guerra a través de la forma: Entrevista a Trinh Minh-ha". Mora [online]. Buenos Aires, v. 23, n. 1, p. 127-140, 2017. Disponible en http://www.scielo. org.ar/scielo.php?script=sci arttext\&pid=S1853-001X2017000100008\&lng=es\&tIng=es. $\quad$ ISSN 1853-001X. Acceso el 15/05/2019.

BALSON, Erika. "'There is No Such Thing as Documentary': An Interview with Trinh T. Minh-ha”. Frieze [online]. 2018. Disponible en https://frieze.com/article/there-no-such-thing-documentary-interview-trinh-t-minh-ha. Acceso el 25/02/2019.

BLAS, Susana. "Trinh T. Minh-ha, en la frontera móvil”. Zehar, Gupúzcoa, n. 58, p. 28-32, 2006. 
CANALS, Roger. "Jean Rouch: un antropólogo de las fronteras". Revista Digital Imagens da Cultura / Cultura das imagens, Lisboa, n. 1, 2011.

COLLIER, John. Visual anthropology: photography as a rechearch method. USA: Hol, Rinemart \& Wiston, 1986.

JULLIER, Laurent. ¿Qué es una buena película? Barcelona: Paidós Comunicación, 2006.

KLUGE, Alexander. A Retrospective. The Goethe Institutes of North America, 1988.

MINH-HA, Trinh T. "El afán totalitario de significado". Archivos de la filmoteca: Revista de estudios históricos sobre la imagen, n. 57-58, 2, p. 223-248, 2007.

MIZUTA, Akira. When the Eye Frames Red. 2012. Disponible en http://trinhminh-ha.squarespace. com/when-the-eye-frames-red/. Acceso el 25/02/2019.

MACDOUGALL, David. "Beyond observational cinema". In: HOCKINGS, Paul (ed.). Principles of visual anthropology. Mouton: Berlín, 1995. p. 115-133.

MOLLER, Natalia. "Reassamblage: un nuevo lenguaje subversivo. El cine etnográfico de Trinh T. Minh-Ha". La fuga, Santiago de Chile, n. 12, p. 1-4, 2011. Disponible en https://www.lafuga.cl/ reassemblage-un-nuevo-lenguaje-subversivo/465. ISSN 0718-5316. Acceso el 25/02/2019.

MOORE, Henrietta. "Trinh T. Minh-ha Observed: Anthropology and Others". In: TAYLOR, Lucien (ed). Visualizing Theory. London: Routledge, 1994. p. 66-72 https://doi.org/10.4324/9781315021614. Acceso el 15/05/2019.

NICHOLS, Bill. La representación de la realidad: cuestiones y conceptos sobre el documental. Barcelona: Paidós Ibérica, 1997.

ORTEGA, María Luisa. "De memorias y olvidos. El documental latinoamericano contemporáneo". Cuadernos Hispanoamericanos, Madrid, n. 679, p. 19-27, 2007.

PIEDRAS, Pablo. "La regla y la excepción: figuraciones de la subjetividad autoral en documentales argentinos de los ochenta y noventa". Revista Toma Uno, Córdoba, n. 1, p. 37-53, 2012.

PLANTINGA, Carl. "What a Documentary Is, After All". The Journal of Aesthetics and Art Criticism, Madrid, n. 63, p. 105-117, 2005. Disponible en https://www.academia.edu/5590880/What_a_Documentary Is After All. Acceso el 25/02/2019.

RICHTER, Hans. "El film, una forma original del arte". En: ROMAGUERA I. RAMIÓ, Joaquin; ALSINA THEVENET, Homero. Textos y manifiestos del cine. Madrid: Cátedra. 1998.

RUBY, Jay. "Revelarse a sí mismo: reflexividad, antropología y cine". In: ADÉRVOL, Elisenda; PÉREZ-TOLÓN, Luis (eds.). Imagen y cultura. Perspectivas del cine etnográfico. Granada: Diputación, 1995. p. 161-201.

SÁNCHEZ SANZ, María Elisa. "Cine etnográfico. Síntesis histórica y algunas reflexiones sobre su desarrollo". Artigrama: Revista del Departamento de Historia del Arte de la Universidad de Zaragoza, Zaragoza, n. 11, p. 269-286, 1994-1995.

SORANZ, Gustavo. "A voz como estratégia narrativa no cinema experimental: sintonias entre a teoria feminista do cinema e as vanguardas artísticas". Doc On-line, n. 23, p. 5-28, 2018. Disponible en http://ojs.labcom-ifp.ubi.pt/index.php/doc/article/view/368. Acceso el 25/02/2019.

STAM, Robert. Teorías del cine. Barcelona: Paidós Ibérica, 2001.

STOTT, William. Documentary Expression and Thirties America. Nueva York: Oxford University Press, 1976.

TORRES SAN MARTíN, Patricia. "Cineastas de América Latina, desacatos de una práctica fílmica". Femmes de cinema, París, n. 22, p. 24-37, 2014. Disponible en https://cinelatino.revues. org/747?lang=es. Acceso el 18/09/2017.

VEGA SOLís, Cristina. "Miradas sobre la otra mujer en el cine etnográfico". Gazeta de Antropología, Jaén, n. 16, 2000. Disponible en http://hdl.handle.net/10481/7502. Acceso el 25/02/2019. 
WORTH, Sol. "Hacia una semiótica del cine etnográfico". In: ARDÉVOL, Elisenda; PÉREZ-TOLÓN, Luís (eds.). Imagen y cultura. Perspectivas del cine etnográfico. Granada: Diputación de Granada. 1995. p. 203-219.

ZIRIÓN, Antonio. "Foco: Trinh T. Minh-ha”. Tabakalera. 2018. Disponible en https://www.tabakalera. eu/es/foco-trinh-t-minh-ha. Acceso el 25/02/2019.

ZUNZUNEGUI, Santos. "Imagen, documental y ficción". Revista de las Ciencias de la Información, Madrid, n. 2, p. 53-62, 1984.

XAVIER, Ismael. El discurso cinematográfico: la opacidad y la transparencia. Buenos Aires: Manantial, 2008.

María Marcos Ramos (mariamarcos@usal.es) es licenciada en Comunicación Audiovisual por la Universidad del País Vasco y Doctora en Comunicación Audiovisual (Premio Extraordinario de Doctorado) por la Universidad de Salamanca. Es profesora ayudante doctora en la Universidad de Salamanca y docente en la institución americana IES Abroad Salamanca. Es miembro colaboradora del Observatorio de Contenidos Audiovisuales de la Universidad de Salamanca donde participa en diferentes investigaciones sobre medios de comunicación y minorías, entre otras temáticas.

\section{COMO CITAR ESTE ARTÍCULO, DE ACUERDO CON LAS NORMAS DE LA REVISTA}

RAMOS, María Marcos. "La mirada femenina a cine etnográfico documental. Reassemblage (Trinh T. Minh-ha 1982)". Revista Estudos Feministas, Florianópolis, v. 29, n. 1, e 66150, 2021.

\section{CONTRIBUCIÓN DE AUTORÍA}

No se aplica

\section{FINANCIACIÓN}

No se aplica.

\section{CONSENTIMIENTO DE USO DE IMAGEN}

No se aplica.

\section{APROBACIÓN DE COMITÉ DE ÉTICA EN INVESTIGACIÓN}

No se aplica

\section{CONFLICTO DE INTERESES}

No se aplica

\section{LICENCIA DE USO}

Este artículo tiene la licencia Creative Commons License CC-BY 4.0 International. Con esta licencia puedes compartir, adaptar, crear para cualquier finalidad, siempre y cuando cedas la autoría de la obra.

\section{HISTORIAL}

Recibido el 09/07/2019

Presentado nuevamente el 13/04/2020

Aprobado el 05/06/2020

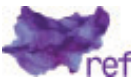

